OPEN ACCESS

Edited by:

Caterina Ledda,

University of Catania, Italy

Reviewed by:

Yuke Tien Fong,

Singapore General Hospital, Singapore

Rudy Foddis,

University of Pisa, Italy

*Correspondence:

Ling Fan

1904893161@qq.com

Xiang-hong Sun

cmusun@126.com

tThese authors have contributed equally to this work

Specialty section:

This article was submitted to

Occupational Health and Safety,

a section of the journal

Frontiers in Public Health

Received: 14 July 2021 Accepted: 19 October 2021 Published: 11 November 2021

Citation:

Xia C-I, Xiao S-q, Wu Q-j, Yu X-y, Xing L-I, Gai L, Xia T-h, Feng H-I,

Zhang X-y, Guo Y, Xu Y-w, Fu T-t, Sun $X$ - $h$ and Fan L (2021) Association Between Passive Smoking and Health

Among Chinese Nurses: A

Cross-Sectional Study.

Front. Public Health 9:741083

doi: 10.3389/fpubh.2021.741083

\section{Association Between Passive Smoking and Health Among Chinese Nurses: A Cross-Sectional Study}

\author{
Chun-ling Xia ${ }^{1 \dagger}$, Shi-qi Xiao ${ }^{1 \dagger}$, Qi-jun Wu ${ }^{2}$, Xin-ying Yu ${ }^{1}$, Lin-lin Xing ${ }^{1}$, Li Gai ${ }^{1}$, \\ Tian-hui Xia ${ }^{1}$, Hui-ling Feng ${ }^{3,4}$, Xin-ying Zhang ${ }^{1}$, Ying Guo ${ }^{1}$, Yi-wei $X u^{1}$, Tong-tong Fu ${ }^{1}$, \\ Xiang-hong Sun ${ }^{1 *}$ and Ling Fan ${ }^{1,3 *}$ \\ ${ }^{1}$ Department of Nursing, Shengjing Hospital of China Medical University, Shenyang, China, ${ }^{2}$ Department of Clinical \\ Epidemiology, Shengjing Hospital of China Medical University, Shenyang, China, ${ }^{3}$ School of Nursing, China Medical \\ University, Shenyang, China, ${ }^{4}$ School of Nursing, Hebei University of Chinese Medicine, Shijiazhuang, China
}

This study aimed to investigate the association between passive smoking and physical and psychological health in Chinese nurses. Participants of this cross-sectional study comprised 2,484 non-smoking nurses. Passive smoking and demographic information were assessed using a self-administered questionnaire. Physical, psychological, and overall health status of nurses were measured using the Cornell Medical Index (CMI) health questionnaire. Multivariate-adjusted odds ratio (OR) and 95\% confidence interval $(\mathrm{Cl})$ for nurses' health were estimated by exposure to passive smoking using unconditional logistic regression models. A total of 1,219 nurses (49.07\%) were exposed to passive smoking. Of these, 609 (24.52\%), 160 (6.44\%), and 587 (23.63\%) nurses had poorer physical, mental, and overall health, respectively. After adjusting for other confounding factors, compared with the non-passive smoking group, passive smoking was associated with poor physical ( $\mathrm{OR}=1.51,95 \% \mathrm{Cl}: 1.25-1.83)$, mental $(\mathrm{OR}=1.48$, $95 \% \mathrm{Cl}: 1.07-2.07)$, and overall $(\mathrm{OR}=1.58,95 \% \mathrm{Cl}: 1.30-1.93)$ health of nurses, respectively. We also carried out subgroup analyses stratified by age, department, and professional title, which showed that most findings supported the main results. This study demonstrated that exposure to passive smoking was a risk factor for overall decreased physical and mental health status among Chinese nurses.

Keywords: passive smoking, health, nurses, CMI, second-hand smoke

\section{INTRODUCTION}

The tobacco pandemic is one of the most severe public health threats. It is well-known that subjection to second-hand smoke (SHS) has prolonged adverse health effects, and there is no safe level of exposure (1). Approximately $65.1 \%$ of non-smokers are exposed to SHS (2). Moreover, 600,000 people die annually from diseases related to SHS exposure (3), accounting for $\sim 1.0 \%$ of global mortality (4). Previous studies have demonstrated that passive smoking is closely related to several diseases, including respiratory (5) and cardiovascular diseases (6), cancers (7), and mental disorders $(8,9)$. Interestingly, research on SHS exposure is increasing among women and children because of their lower smoking rates, indicating that passive smoking is a more serious public health problem than active smoking in these groups (10). 
Importantly, non-smokers may be subjected to SHS in public places, the workplace, or in their home. Many countries have issued smoke-free policies to help reduce SHS exposure in public places and workplaces, but not in the home (11). Because nurses work in hospitals, which are smoke-free environments, they are an appropriate target group to examine the relationship between exposure to SHS in non-workplace environments and health. Moreover, nurses can respond accurately to technically worded questionnaires because of their health knowledge and their ability to provide comprehensive information regarding various diseases.

However, few studies have investigated the association between SHS and sub-health, defined as a decline in vitality, physiological function, and capacity for adaptation, without the presence of clinical or sub-clinical disease (12). Importantly, the Cornell Medical Index (CMI) (Chinese version) is a self-administered form with excellent reliability (Cronbach's $\alpha=0.970$ ), and is widely used as a sensitive indicator of health status $(13,14)$. Several longitudinal and cross-sectional studies have among participants of different genders, ages, and occupations (15-17).

Therefore, to our knowledge, this is the first cross-sectional study investigating the relationship between SHS and the CMI scores of non-smoking nurses. This study was conducted in a hospital in northeast China.

\section{METHODS}

\section{Study Design and Population}

This study was a descriptive cross-sectional study conducted among a large sample of nurses. Participants were enrolled in the Health Evaluation of Occupational Nurses, which is a cohort study taking place at the Shengjing Hospital of China Medical University in Shenyang Liaoning Province, China. The cohort study was launched in 2013 to analyze the effects of genetic and environmental interactions on nurses' health.

\section{Data Collection}

In the study, participants completed a self-administered questionnaire regarding their lifestyle and health status and donated a peripheral blood sample during a health check-up at the baseline survey every 2 years. All subjects voluntarily participated in this study and provided informed consent. This study was approved by the Ethics Committee of Shengjing Hospital of China Medical University.

The inclusion criteria were qualified nurses who underwent the annual physical examination. The exclusion criteria were nurses who were on sick leave or absent from the physical examination. A total of 2,635 participants were recruited to the present study. To examine the effect of passive smoking on health status by excluding the effect of active smoking, we limited participants to those with negligible experience of active smoking in their lifetime. Active smokers were defined as those who smoked at least one cigarette per day for more than 6 months. After excluding active smokers, there were 2,570 non-smokers left. We further excluded those missed data for SHS exposure and health status $(n=23)$. We excluded 63 male nurses in the present study. Thus, the present study included 2,484 non-smokers in the final analysis, comprising 1,219 $(49.07 \%)$ passive smokers and 1,265 (50.93\%) non-passive smokers.

\section{Exposure Assessment}

The self-administered questionnaire included the following demographic characteristics and lifestyle factors: alcohol consumption, smoking status, exposure to passive smoking, education level, health status, regular diet, sleep duration and

TABLE 1 | Participant characteristics according to exposure to SHS $(n=2,484)$.

\begin{tabular}{|c|c|c|c|c|}
\hline & Total & $\begin{array}{l}\text { Non-SHS } \\
n=1,265\end{array}$ & $\begin{array}{c}\text { SHS } \\
n=1,219\end{array}$ & $P$-value \\
\hline Age (years) & & & & $<0.05$ \\
\hline$\leq 35$ & 1,924 (77.46) & $956(75.57)$ & $968(79.41)$ & \\
\hline$>35$ & $560(22.54)$ & $309(24.43)$ & $251(20.59)$ & \\
\hline $\begin{array}{l}\text { Working duration } \\
\text { (years) }\end{array}$ & $10.22 \pm 7.27$ & $10.64 \pm 7.64$ & $9.78 \pm 6.83$ & $<0.05$ \\
\hline Profession title & & & & $<0.05$ \\
\hline Nurse & 729 (29.35) & $339(26.80)$ & 390 (31.99) & \\
\hline Senior nurse & $1,417(57.04)$ & 729 (57.63) & $688(56.44)$ & \\
\hline $\begin{array}{l}\text { Supervisor or } \\
\text { nursing professor }\end{array}$ & 338 (13.61) & $197(15.57)$ & $141(11.57)$ & \\
\hline Department & & & & $<0.05$ \\
\hline Medical & $651(26.21)$ & 304 (24.03) & $347(28.46)$ & \\
\hline Surgical & $523(21.05)$ & $251(19.84)$ & $272(22.31)$ & \\
\hline $\begin{array}{l}\text { Obstetrics and } \\
\text { gynecology }\end{array}$ & 331 (13.33) & $166(13.12)$ & $165(13.54)$ & \\
\hline Pediatrics & $288(11.59)$ & $157(12.41)$ & $131(10.75)$ & \\
\hline Outpatient & $353(14.21)$ & 201 (15.89) & $152(12.47)$ & \\
\hline Other & 338 (13.61) & $186(14.71)$ & $152(12.47)$ & \\
\hline Alcohol consumption & & & & $<0.05$ \\
\hline No & 2,306 (92.83) & 1,189 (93.99) & $1,117(91.63)$ & \\
\hline Yes & $178(7.17)$ & $76(6.01)$ & $102(8.37)$ & \\
\hline Employment type & & & & $<0.05$ \\
\hline Contract & $2,048(82.45)$ & $1,010(79.84)$ & 1,038 (85.15) & \\
\hline Others & $436(17.55)$ & $255(20.16)$ & $181(14.85)$ & \\
\hline Regular diet & & & & $<0.05$ \\
\hline Yes & $1,544(62.16)$ & 825 (65.22) & 719 (58.98) & \\
\hline No & $940(37.84)$ & 440 (34.78) & $500(41.02)$ & \\
\hline $\begin{array}{l}\text { Time spent with } \\
\text { patients }\end{array}$ & & & & $<0.05$ \\
\hline$>75 \%$ & 1,669 (67.19) & 875 (69.17) & $794(65.14)$ & \\
\hline$\leq 75 \%$ & $815(32.81)$ & $390(30.83)$ & $425(34.86)$ & \\
\hline Sleep duration (hours) & & & & $<0.05$ \\
\hline$<6$ & $920(37.04)$ & 439 (34.70) & $481(39.46)$ & \\
\hline$\geq 6$ & $1,564(62.96)$ & $826(65.30)$ & 738 (60.54) & \\
\hline Sleep quality & & & & $<0.05$ \\
\hline Good & 1,048 (42.19) & $574(45.37)$ & $474(38.88)$ & \\
\hline Average & $1,059(42.63)$ & $521(41.19)$ & $538(44.14)$ & \\
\hline Poor & 377 (15.18) & $170(13.44)$ & 207 (16.98) & \\
\hline
\end{tabular}

SHS, second-hand smoke. 
sleep quality, nursing department, employment type, working seniority, professional title, and contact time with patients. The details of this description were introduced in previous article (13).

The questionnaire examined whether the nurses were active smokers, and if so, the number of cigarettes they smoked every day. Non-smokers were asked whether they were passive smokers. Exposure level to passive smoking was assessed using a single question: "Have you inhaled the smoke of others' cigarettes (i.e., smokers) at home, in an office, or elsewhere for more than 15 minutes one day a week on average in the last year?" Responses were either "yes" or "no."

Participants' physical and psychological health condition was measured using a modified version of the CMI health questionnaire, which comprised 18 parts and a total of 195 questions. Considering the adverse effects reported by published studies (12), subscales of the eye and ear, nervous system, respiratory system, skin, and digestive tract were used to investigate the corresponding symptoms. The questionnaire was divided into sections: A-L were related to physical disorders, and $\mathrm{M}-\mathrm{R}$ referred to psychiatric/psychological morbidity. Thus, in addition to summing the total positive responses, we scored the positive responses for each of the two categories. The score range by the CMI was 0-195, and the range of the present population was 31-124, with higher scores indicating poorer levels of physical and mental health status. According to the article by $\mathrm{Xu}$ et al. (13), we demarcated a CMI total score of $\geq 40$ as poor health status and $M-R$ score of $\geq 20$ as poor mental health. Since there was no scientific research to demark good physical health from poor conditions, we classified physical health into two categories by average: A-L score of $>30$ as poor physical health and A-L score of $\leq 30$ as good physical health, which was often handled this way in statistics.

\section{Statistical Analysis}

Descriptive statistics were performed to screen and compare participant characteristics between groups. Continuous variables were reported using the mean \pm standard deviation, and categorical variables were represented by counts and percentages. To compare differences between groups, independent sample Student's $t$-tests were conducted for continuous variables, and the Chi-square test was used for categorical variables. Logistic regression analyses were used to calculate risk estimates to assess associations between passive smoking and health status. We first applied a model adjustment for age (years) to calculate the risk estimates of passive smoking on health. In the second regression model, we further adjusted for professional title (nurse, senior nurse, supervisor, or nursing professor); department (medical, surgical, obstetrics and gynecology, pediatrics, outpatient, other); alcohol consumption (yes or no); employment type (contract, other); regular diet (yes or no); time spent with patients $(>75 \%$ or $\leq 75 \%)$; sleep duration $(<6$ or $\geq 6 \mathrm{~h}$ ); and sleep quality (good, average, or poor). In addition, we calculated adjusted risk estimates in subgroup analyses and interaction analyses stratified by age, professional title, and department. All analyses were conducted using SPSS 21.0 (IBM, Armonk, New York, USA). All
TABLE 2 | Association between SHS and health status.

\begin{tabular}{ccccc}
\hline & Total & $\begin{array}{c}\text { Non-SHS } \\
\boldsymbol{n = 1 , 2 6 5}\end{array}$ & $\begin{array}{c}\text { SHS } \\
\boldsymbol{n}=\mathbf{1 , 2 1 9}\end{array}$ & P-value \\
\hline Physical health & & & & $<0.05$ \\
A-L score $\leq 30$ & $1,875(75.48)$ & $1,008(79.68)$ & $867(71.12)$ & \\
A-L score $>30$ & $609(24.52)$ & $257(20.32)$ & $352(28.88)$ & \\
Mental health & & & & $<0.05$ \\
M-R score $<20$ & $2,324(93.56)$ & $1,199(94.78)$ & $1,125(92.29)$ & \\
M-R score $\geq 20$ & $160(6.44)$ & $66(5.22)$ & $94(7.71)$ & \\
CMI & & & & $<0.05$ \\
Total score $<40$ & $1,897(76.37)$ & $1,021(80.71)$ & $876(71.86)$ & \\
Total score $\geq 40$ & $587(23.63)$ & $244(19.29)$ & $343(28.14)$ & \\
\hline
\end{tabular}

SHS, second-hand smoke.

TABLE 3 | ORs and 95\% Cls for nurses' health according to exposure to SHS among non-smokers.

\begin{tabular}{|c|c|c|}
\hline & $\begin{array}{l}\text { Non-SHS } \\
n=1,265\end{array}$ & $\begin{array}{c}\text { SHS } \\
n=1,219\end{array}$ \\
\hline \multicolumn{3}{|l|}{ Physical health } \\
\hline Age-adjusted OR (95\% Cl) & Ref. & $1.59(1.32-1.91)$ \\
\hline Multivariate-adjusted OR* $(95 \%$ Cl) & Ref. & $1.51(1.25-1.83)$ \\
\hline \multicolumn{3}{|l|}{ Mental health } \\
\hline Age-adjusted OR (95\% Cl) & Ref. & $1.51(1.09-2.09)$ \\
\hline Multivariate-adjusted OR* (95\% Cl) & Ref. & $1.48(1.07-2.07)$ \\
\hline \multicolumn{3}{|l|}{$\mathrm{CMl}$} \\
\hline Age-adjusted OR (95\% Cl) & Ref. & $1.63(1.35-1.97)$ \\
\hline Multivariate-adjusted $\mathrm{OR}^{\star}(95 \% \mathrm{Cl})$ & Ref. & $1.58(1.30-1.93)$ \\
\hline
\end{tabular}

SHS, second-hand smoke; Cl, confidence interval; OR, odds ratio.

*Adjusted for age (categorical variable), profession title, department, alcohol consumption, employment type, regular diet, time spent with patients, sleep duration, and sleep quality.

statistical tests were two-sided and statistical significance was set at $p<0.05$.

\section{RESULTS}

The basic characteristics of participants stratified by passive smoking are reported in Table $\mathbf{1}$. Our study included 2,484 female nurses, and $49 \%$ of them were exposed to passive smoking. Nurses who were exposed to passive smoking were younger, worked mostly in the medical and surgical departments, had lower professional titles, were likelier to consume alcohol, had irregular diets, had shorter sleep durations, and had poor sleep quality $(p<0.05)$.

Table 2 shows that nurses exposed to passive smoking had poor overall health than the non-exposed group (28.14 and 19.29\%, respectively, $p<0.05)$, and significant declines in physical $(28.88$ and $20.32 \%$, respectively, $p<0.05$ ) and mental health (7.71 and 5.22\%, respectively, $p<0.05$ ).

Nurses' exposure to passive smoking was associated with health status risk (see Table 3). Specifically, nurses who were exposed to passive smoking had poor physical, mental, 
TABLE 4 | Subgroup and interaction analysis.

\begin{tabular}{|c|c|c|c|c|c|c|c|c|c|}
\hline & \multicolumn{3}{|c|}{ Physical health } & \multicolumn{3}{|c|}{ Mental health } & \multicolumn{3}{|c|}{ CMI } \\
\hline & Non-SHS & SHS & $p^{*}$ & Non-SHS & SHS & $p^{*}$ & Non-SHS & SHS & $p^{\star}$ \\
\hline Age (years) & & & 0.86 & & & 0.93 & & & 0.19 \\
\hline$\leq 35$ & Ref. & $1.52(1.23-1.90)$ & & Ref. & $1.50(1.03-2.17)$ & & Ref. & $1.73(1.38-2.16)$ & \\
\hline$>35$ & Ref. & $1.47(0.97-2.24)$ & & Ref. & $1.31(0.60-2.86)$ & & Ref. & $1.13(0.74-1.75)$ & \\
\hline Profession title & & & 0.39 & & & 0.40 & & & 0.04 \\
\hline Nurse & Ref. & $1.62(1.13-2.33)$ & & Ref. & $1.96(0.98-3.91)$ & & Ref. & 2.28 (1.56-3.33) & \\
\hline Senior nurse & Ref. & $1.56(1.21-2.01)$ & & Ref. & $1.44(0.94-2.19)$ & & Ref. & $1.45(1.12-1.87)$ & \\
\hline Supervisor or nursing professor & Ref. & $1.04(0.58-1.85)$ & & Ref. & $0.86(0.32-2.36)$ & & Ref. & $1.06(0.59-1.91)$ & \\
\hline Department & & & 0.75 & & & 0.86 & & & 0.19 \\
\hline Medical & Ref. & $1.87(1.27-2.76)$ & & Ref. & $1.08(0.57-2.07)$ & & Ref. & $2.13(1.44-3.14)$ & \\
\hline Surgical & Ref. & $1.37(0.91-2.07)$ & & Ref. & 1.67 (0.83-3.37) & & Ref. & $1.77(1.16-2.70)$ & \\
\hline Obstetrics and gynecology & Ref. & $1.27(0.68-2.39)$ & & Ref. & $1.07(0.28-4.15)$ & & Ref. & $0.81(0.40-1.62)$ & \\
\hline Pediatrics & Ref. & $1.51(0.84-2.72)$ & & Ref. & $1.69(0.49-5.81)$ & & Ref. & $1.65(0.89-3.07)$ & \\
\hline Outpatient & Ref. & $1.35(0.83-2.20)$ & & Ref. & $2.21(1.00-4.88)$ & & Ref. & $1.13(0.69-1.88)$ & \\
\hline Other & Ref. & $1.52(0.90-2.55)$ & & Ref. & $1.52(0.68-3.39)$ & & Ref. & $1.70(1.02-2.84)$ & \\
\hline
\end{tabular}

SHS, second-hand smoke.

${ }^{*} \mathrm{p}$ for interaction.

and overall health. The power of our study was 0.9977 after calculation.

Subgroup analyses stratified by age, professional title, and department (Table 4) showed that the direction of most findings were consistent with the main results; however, not all results showed statistical significance.

\section{DISCUSSION}

\section{Main Findings}

To our knowledge, this is the first study to investigate passive smoking and nurses' health using CMI as a measurement indicator among northeastern Chinese female nurses. We found a significant association between passive smoking and nurses' health. Specifically, exposure to passive smoking deteriorated nurses' physical, mental, and overall health. The results of subgroup analysis also supported the main findings.

\section{Comparison With Other Studies}

Our results suggest that exposure to SHS is related to physical and mental health, which is consistent with previous studies (18-21). For example, a study on environmental tobacco smoke (ETS) in China indicated that the estimated acute health risks after $1-2 \mathrm{~h}$ of ETS exposure would be $29 \%$ (20). Moreover, a meta-analysis of 11 cross-sectional studies demonstrated that exposure to SHS among non-smokers was significantly associated with depressive symptoms and psychological distress (21). A South Korean study investigated the lifetime costs and health outcomes of adult women exposed to SHS at home, and found that women exposed to SHS had higher health expenditures and lower life expectancies (22). In addition, health status is related to the amount of SHS. Specifically, women who live with smokers have poorer health than women who do not, and the more smokers they live with, the worse their health (23). However, our findings were inconsistent with several studies $(24,25)$. For example, a UK national population-based prospective cohort study demonstrated that there was a non-significant association between objectively measured SHS exposure and poor mental health (24). This can be explained from a cultural perspective. That is, traditional Chinese Confucianism advocates a modest and harmonious approach, which prevents people from directly expressing their emotions. Thus, when individuals encounter unpleasant situations such as exposure to SHS, most opt to endure the circumstances, rather than prevent it (26). Variations in research objects and mental health assessment methods may also explain the contradictory evidence. Thus, it is necessary to conduct further research in this field.

\section{Potential Biological Mechanisms}

SHS is a complex reactive mixture containing over 4,700 chemicals, including hazardous amines, carbonyls, hydrocarbons, and metals $(27,28)$. Moreover, mainstream tobacco smoke contains 11 strains of human carcinogens which can cause various types of cancer (29). Nicotine is the main component of tobacco and is a sympathetic stimulant that prompts the release of catecholamines and other neurotransmitters $(30,31)$. Cotinine, which is the main product of nicotine after primary metabolism, is associated with psychological distress and the risk of future mental illness (32). Thus, exposure to SHS can increase the levels of corticotropin releasing hormone and adrenocorticotropic hormone, and gradually affects individuals' emotions and cognitions (33-35). Previous studies indicate that passive smoking is related to endocrine and metabolic changes (36-39), which may lead to sub-health status.

\section{Strengths and Limitations}

Our study has several strengths. First, this is the first study investigating nurses' health and passive smoking using CMI as a measurement indicator. Second, this study has a large 
sample size and can be used for subgroup analysis. Third, the inclusion of nurses as study participants can reduce measurement error, because their health knowledge and abilities can provide comprehensive and accurate information. Finally, we performed a subgroup analysis of passive smoking, and the results supported our main findings.

However, our study has several limitations. First, this is a cross-sectional study which cannot determine the causal relationship between passive smoking and health status. Second, the exposure to passive smoking was self-reported. We did not measure biomarkers (such as cotinine levels); thus, the actual prevalence of SHS exposure may have been underestimated. Moreover, we did not investigate the amount of passive smoking; therefore, we could not further explain the relationship between the dose of passive smoking and nurses' health. In addition, in other studies, passive smoking environments were divided into public places, workplaces, and in the home (6). In our study, the subjects were nurses who worked in a smoke-free hospital, who were exposed to SHS both in public places and at home. However, passive smoking in public places and in the home could not be separated. Finally, passive smoking is related to many factors, such as gender, age, alcohol consumption, lifestyle, socio-economic status, and allergic sensitization. In our study, we adjusted for age, duration of service, professional title, department, alcohol consumption, employment type, diet, contact time with patients, sleep duration and sleep quality. Nevertheless, some potential confounding factors remain, but may have little impact on our results. Although this study has a large sample size and can be used for subgroup analysis, not all results showed statistical significance which may be attributed to limited sample sizes in specific subgroups. Further studies are warranted to pay more attention to solve this issue in the future.

\section{Conclusions and Interpretations}

In conclusion, our study provides novel evidence for the relationship between SHS exposure and health among female

\section{REFERENCES}

1. National Center for Chronic Disease Prevention and Health Promotion (US) Office on Smoking and Health. The Health Consequences of Smoking--50 Years of Progress: A Report of the Surgeon General. Atlanta, GA Centers for Disease Control and Prevention (US) (2014).

2. Zheng Y, Ji Y, Dong H, Chang C. The prevalence of smoking, second-hand smoke exposure, and knowledge of the health hazards of smoking among internal migrants in 12 provinces in China: a cross-sectional analysis. BMC Public Health. (2018) 18:655. doi: 10.1186/s12889-018-5549-8

3. WHO World Health Organization. WHO Report on the Global Tobacco Epidemic. (2013). Available online at: https://escholarship.org/uc/item/ 5t06910t (accessed May 10, 2021).

4. Oberg M, Jaakkola MS, Woodward A, Peruga A, Prüss-Ustün A. Worldwide burden of disease from exposure to second-hand smoke: a retrospective analysis of data from 192 countries. Lancet. (2011) 377:13946. doi: 10.1016/S0140-6736(10)61388-8

5. GBD Chronic Respiratory Disease Collaborators. Prevalence and attributable health burden of chronic respiratory diseases, 1990-2017: a systematic analysis for the global burden of disease study 2017. Lancet Respir Med. (2020) 8:585-96. doi: 10.1016/S2213-2600(20)3 0105-3 nurses in China. Exposure to SHS is associated with overall, physical, and mental health.

\section{DATA AVAILABILITY STATEMENT}

The raw data supporting the conclusions of this article will be made available by the authors, without undue reservation.

\section{ETHICS STATEMENT}

The studies involving human participants were reviewed and approved by Shengjing Hospital of China Medical University. The patients/participants provided their written informed consent to participate in this study.

\section{AUTHOR CONTRIBUTIONS}

LF, S-qX, X-hS, and C-lX: conceptualization and funding acquisition. T-hX, Q-jW, and H-lF: contributed materials/analysis tools. T-tF, YG, L-IX, X-yY, and LG: helped in data collection and field operations. All authors helped prepare the manuscript and approved the submitted version.

\section{FUNDING}

This project was funded by the Department of Science and Technology of Liaoning Province (Grant Number 2018225005).

\section{ACKNOWLEDGMENTS}

We gratefully acknowledge the friendly contribution of the voluntary collaboration of the participants, the Department of Nursing and technical assistance of Wei Zhang in Computer Center from Shengjing Hospital, Liaoning Province.
6. Khoramdad M, Vahedian-Azimi A, Karimi L, Rahimi-Bashar F, Amini $\mathrm{H}$, Sahebkar A. Association between passive smoking and cardiovascular disease: a systematic review and meta-analysis. IUBMB Life. (2020) 72:67786. doi: 10.1002/iub.2207

7. Kim AS, Ko HJ, Kwon JH, Lee JM. Exposure to secondhand smoke and risk of cancer in never smokers: a meta-analysis of epidemiologic studies. Int J Environ Res Public Health. (2018) 15:1981. doi: 10.3390/ijerph15091981

8. Chen CY, Chang CM, Lin HL, Chu CL. The association between exposure to second-hand smoke and major depressive disorder in perimenopausal women: results from a population-based study. Ann Med. (2018) 50:596604. doi: 10.1080/07853890.2018.1534264

9. Wang H, Li F, Zhang Y, Jiang F, Zhang J. The association between exposure to secondhand smoke and psychological symptoms among Chinese children. BMC Public Health. (2019) 19:923. doi: 10.1186/s12889-019-7006-8

10. Wipfli HL, Samet JM. Second-hand smoke's worldwide disease toll. Lancet. (2011) 377:101-2. doi: 10.1016/S0140-6736(10)61922-8

11. Ngobese SP, Egbe CO, Londani M, Ayo-Yusuf OA. Non-smoker's exposure to second-hand smoke in South Africa during 2017. Int J Environ Res Public Health. (2020) 17:8112. doi: 10.3390/ijerph17218112

12. Feng S, Liu W, Zuo S, Xie T, Deng H, Zhang Q, et al. Impaired function of the intestinal barrier in a novel sub-health rat model. Mol Med Rep. (2016) 13:3459-65. doi: 10.3892/mmr.2016.4978 
13. Feng HL, Qi XX, Xia CL, Xiao SQ, Fan L. Association between night shift and sleep quality and health among Chinese nurses: a cross-sectional study. $J$ NursManag. (2021) 29:2123-31. doi: 10.1111/jonm.13351

14. Weaver CA, Ko YH, Alexander ER, Pao YL, Ting N. The Cornell Medical Index as a predictor of health in a prospective cardiovascular study in Taiwan. Am J Epidemiol. (1980) 111:113-24. doi: 10.1093/oxfordjournals.aje.a112861

15. Didikoglu A, Maharani A, Tampubolon G, Canal MM, Payton A, Pendleton N. Longitudinal sleep efficiency in the elderly and its association with health. J Sleep Res. (2020) 29:e12898. doi: 10.1111/jsr.12898

16. Sui G, Liu G, Jia L, Wang L, Yang G. The association between ambient air pollution exposure and mental health status in Chinese female college students: a cross-sectional study. Environ SciPollut Res Int. (2018) 25:2851728524. doi: 10.1007/s11356-018-2881-6

17. Osaka R, Nanakorn S, Chusilp K. Cornell medical index: a comparative study on health problems among Thai and Japanese nursing students. Southeast Asian J Trop Med Public Health. (1998) 29:293-8.

18. Kim NH, Choi H, Kim NR, Shim JS, Kim HC. Secondhand smoke exposure and mental health problems in Korean adults. Epidemiol Health. (2016) 38:e2016009. Published 2016 Mar 14. doi: 10.4178/epih.e2016009

19. Wang R, Zhang P, Lv X, Gao C, Song Y, Li Z, et al. Association between passive smoking and mental distress in adult never-smokers: a cross-sectional study. BMJ Open. (2016) 6:e011671. doi: 10.1136/bmjopen-2016-011671

20. Li L, Ho SSH, Chow JC, Watson JG, Lee FS, Cui L, et al. Characterization and health risk assessment of PM2.5-bound organics inside and outside of Chinese smoking lounges. Chemosphere. (2017) 186:438-45. doi: 10.1016/j.chemosphere.2017.08.006

21. Zeng YN, Li YM. Secondhand smoke exposure and mental health in adults: a meta-analysis of cross-sectional studies. Soc Psychiatry PsychiatrEpidemiol. (2016) 51:1339-48. doi: 10.1007/s00127-015-1164-5

22. Lee J, Han AR, Choi D, Lim KM, Bae S. Modeling lifetime costs and health outcomes attributable to secondhand smoke exposure at home among Korean adult women. BMJ Open. (2017) 7:e013292. doi: 10.1136/bmjopen-2016-013292

23. Sobotova L, Liu YH, Burakoff A, Sevcikova L, Weitzman M. Household exposure to secondhand smoke is associated with decreased physical and mental health of mothers in the USA. Matern Child Health J. (2011) 15:12837. doi: 10.1007/s10995-009-0549-z

24. Lam E, Kvaavik E, Hamer M, Batty GD. Association of secondhand smoke exposure with mental health in men and women: cross-sectional and prospective analyses using the U.K. Health and Lifestyle Survey. Eur Psychiatry. (2013) 28:276-81. doi: 10.1016/j.eurpsy.2012.04.001

25. Kandel DB, Schaffran C, Griesler PC, Hu MC, Davies M, Benowitz N. Salivary cotinine concentration versus self-reported cigarette smoking: three patterns of inconsistency in adolescence. Nicotine Tob Res. (2006) 8:52537. doi: 10.1080/14622200600672732

26. Bandiera FC, Arheart KL, Caban-Martinez AJ, Fleming LE, McCollister K, Dietz NA, et al. Secondhand smoke exposure and depressive symptoms. Psychosom Med. (2010) 72:68-72. doi: 10.1097/PSY.0b013e3181c6c8b5

27. Torres S, Merino C, Paton B, Correig X, Ramírez N. Biomarkers of exposure to secondhand and thirdhand tobacco smoke: recent advances and future perspectives. Int J Environ Res Public Health. (2018) 15:2693. doi: 10.3390/ijerph15122693

28. Talhout R, Schulz T, Florek E, van Benthem J, Wester P, Opperhuizen A. Hazardous compounds in tobacco smoke. Int J Environ Res Public Health. (2011) 8:613-28. doi: 10.3390/ijerph8020613

29. IARC Working Group on the Evaluation of Carcinogenic Risks to Humans. Tobacco smoke and involuntary smoking. IARC Monogr Eval Carcinog Risks Hum. (2004) 83:1-1438.
30. Lee W, Hwang SH, Choi H, Kim H. The association between smoking or passive smoking and cardiovascular diseases using a Bayesian hierarchical model: based on the 2008-2013 Korea Community Health Survey. Epidemiol Health. (2017) 39:e2017026. doi: 10.4178/epih.e20 17026

31. P Panagiotakos DB, Pitsavos C, Chrysohoou C, Skoumas J, Masoura C, Toutouzas $\mathrm{P}$, et al. Effect of exposure to secondhand smoke on markers of inflammation: the ATTICA study. Am J Med. (2004) 116:145-50. doi: 10.1016/j.amjmed.2003. 07.019

32. Hamer M, Stamatakis E, Batty GD. Objectively assessed secondhand smoke exposure and mental health in adults: cross-sectional and prospective evidence from the Scottish Health Survey. Arch Gen Psychiatry. (2010) 67:850-5. doi: 10.1001/archgenpsychiatry. 2010.76

33. Sellini M, Sartori MP, Letizia C, Dimitriadis E, Bassi R, Baccarini S. Changes in the levels of ACTH and cortisol after passive exposure to cigarette smoke in smokers and non-smokers. Boll Soc Ital BiolSper. (1989) 65:365-9.

34. Underner M, Perriot J, Peiffer G, Meurice JC. Influence of tobacco smoking on the risk of developing asthma. Rev Mal Respir. (2015) 32:11037. doi: 10.1016/j.rmr.2014.07.014

35. Bao AM, Meynen G, Swaab DF. The stress system in depression and neurodegeneration: focus on the human hypothalamus. Brain Res Rev. (2008) 57:531-53. doi: 10.1016/j.brainresrev.2007.04.005

36. Barupal DK, Pinkerton KE, Hood C, Kind T, Fiehn O. Environmental tobacco smoke alters metabolic systems in adult rats. Chem Res Toxicol. (2016) 29:1818-27. doi: 10.1021/acs.chemrestox.6b00187

37. Cuschieri S, Vassallo J, Calleja N, Mamo J. Relationship of past, present, and passive smoking with sociodemographic, anthropometric, biochemical, and dysglycemic profiles. J Diabetes. (2019) 11:87-9. doi: 10.1111/1753-0407.12844

38. Kang J, Kong E, Choi J. Associations of urinary cotinine-verified active and passive smoking with thyroid function: analysis of population-based nationally representative data. Thyroid. (2018) 28:583-92. doi: 10.1089/thy.2017.0567

39. Wu J, Pan G, Huang YT, Liu DK, Zeng HX, Zhou XJ, et al. Effects of passive smoking and its duration on the prevalence of prediabetes and type 2 diabetes mellitus in Chinese women. Aging. (2020) 12:94406. doi: 10.18632/aging.103217

Conflict of Interest: The authors declare that the research was conducted in the absence of any commercial or financial relationships that could be construed as a potential conflict of interest.

Publisher's Note: All claims expressed in this article are solely those of the authors and do not necessarily represent those of their affiliated organizations, or those of the publisher, the editors and the reviewers. Any product that may be evaluated in this article, or claim that may be made by its manufacturer, is not guaranteed or endorsed by the publisher.

Copyright (C 2021 Xia, Xiao, Wu, Yu, Xing, Gai, Xia, Feng, Zhang, Guo, Xu, Fu, Sun and Fan. This is an open-access article distributed under the terms of the Creative Commons Attribution License (CC BY). The use, distribution or reproduction in other forums is permitted, provided the original author(s) and the copyright owner(s) are credited and that the original publication in this journal is cited, in accordance with accepted academic practice. No use, distribution or reproduction is permitted which does not comply with these terms. 